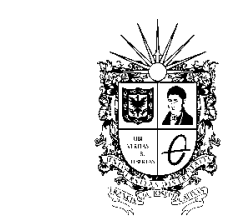

UNIVERSIDAD DISTRITAL FRANCISCO JOSE DE CALDAS

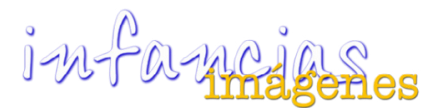

http://revistas.udistrital.edu.co/ojs/index.php/infancias

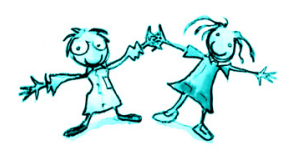

SEPARATA ESPECiAL

\title{
Literatura, fantasía y realidad
}

\author{
Celso Román ${ }^{1}$
}

\section{Resumen}

La conferencia se basa en la exposición de los siguientes temas: la palabra como entidad generadora de realidades en nuestra mente, a la vez que es una herramienta creadora de mundos; la metáfora como un recurso literario que identifica dos términos entre los cuales existe alguna semejanza, asumida como instrumento que por comparación permite apropiar ideas del mundo; la palabra en relación con el habla humana, más allá de la

IV simple comunicación de un mensaje, asumida como transformadora de la realidad a lo largo de la historia; el mito de creación como explicación mágica del mundo por todos los pueblos; la leyenda, como un encuentro entre dioses y humanos, ya sea para ayudarles, o para ponerles condiciones; los cuentos de hadas y populares como historias que les suceden, simple y llanamente, a los seres humanos y son el resultado de la confluencia entre Europa y América, a lo largo de varios siglos. La conferencia presentará diversos textos resultado tanto de la investigación como de la creación personal del autor.

\section{Desarrollo}

En esta conferencia se propone un recorrido por el lenguaje como instrumento de apropiación del entorno, referido a la explicación del universo a lo largo de la historia de la humanidad, por el camino del mito de creación, la leyenda, y el cuento tradicional, enfatizando en cómo la literatura se convierte en un vehículo para comprender, en una perspectiva histórica, los entornos naturales, sociales y culturales.

\section{La palabra como entidad generadora de realidades}

En la infancia de la humanidad los antepasados trataban de sobrevivir en un medio hostil, expuestos a las fieras y la inclemencia del tiempo. Ante los fenómenos naturales avasalladores, era necesario explicar el origen del mundo y de las cosas: ¿Quién nos puso aquí? ¿Cómo fueron creados el mundo y los seres humanos?

La palabra fue el instrumento que nos permitió explicar la realidad, ya que el habla humana va más allá de la simple transmisión de un mensaje, como podría considerarse con ciertas especies animales que aparentemente tienen un lenguaje — hormigas, abejas, loros y monos-.

La palabra ha sido un instrumento de transformación de la realidad a lo largo de la historia y su acción se manifiesta en la formación de los primeros conglomerados urbanos, con la invención de la agricultura, la tecnología, el arte y la ciencia, mediados siempre por el lenguaje.

El lenguaje permite construir en la mente ideas de la realidad, a partir de la percepción que tenemos del mundo a través de los sentidos y es así como algunas palabras, por ejemplo carreta, casa, gato o perro, convocan imágenes personales y únicas, acordes con nuestras emociones y experiencias.

Cuando en una conversación o en un texto aparecen palabras desconocidas como cuja (una cama hecha de madera y cuero), curiara (sinónimo de canoa), canalete (remo), timbo (recipiente plástico),

\footnotetext{
1 Escritor de literatura infantil. Siendo médico veterinario, optó por la literatura y el arte; ingresó en la Facultad de Artes de la Universidad Nacional de Colombia y continuó sus estudios de posgrado en el Pratt Institute de Nueva York. Ha sido escultor y profesor de Bellas Artes. Ha publicado: Los amigos del hombre (Premio Enka, 1979), Las cosas de la casa (Premio ACLIJ, 1988), El imperio de las cinco lunas (Premio Latinoamericano de Literatura Juvenil, Norma-Fundalectura), entre otros.
} 
por comparación las podemos apropiar en nuestra mente como las nuevas realidades mentales que ellas representan.

Se puede afirmar entonces que lo que está fuera de nosotros, en el mundo que percibimos con los sentidos, es lo real que se puede tocar, ver, percibir sensorialmente, mientras que la realidad es lo que se construye en la mente que piensa.

\section{La metáfora como un recurso literario}

Metáfora es un tropo o recurso literario. Proveniente del griego meta, "más allá", y forein, "pasar, Ilevar", consiste en identificar dos términos entre los cuales existe alguna semejanza. Etimológicamente la palabra proviene del latín parábola, que remonta a la narración de un suceso y su representación en la mente. En esta conferencia se asume como un instrumento que permite apropiar ideas del mundo por comparación. Para Humberto Maturana (1997), quien define el lenguajear como la facultad que nos diferencia de los demás seres vivos y permite hallar el sentido de lo humano, la palabra es la herramienta que permite crear mundos, unificar fragilidades y re-crear; es decir, volver a crear a la humanidad en relación con el otro.

Es interesante anotar cómo cuando los europeos Ilegaron a América encontraron una enorme diversidad de plantas, animales y culturas nunca antes vistas, las cuales fueron apropiadas mediante el lenguaje, la religión y la cultura. Se pueden citar numerosos ejemplos de este proceso en lo narrado por los cronistas de Indias, cuando vieron los armadillos por primera vez. Don Gonzalo Fernández de Oviedo, en su Historia general y natural de las Indias, recurre a referentes familiares que permiten deshacer el asombro y la desconfianza que produce una criatura extraña:

Estos animales son de cuatro pies, y la cola y todo él es de tez, la piel como cobertura o pellejo de lagarto, pero es entre blanco y pardo, tirando más a la color blanca, y es de la facción y hechura ni más ni menos que un caballo encubertado (con armadura para el combate), con sus costaneras y coplón, y en todo por todo, y por debajo de lo que muestran las costaneras y cubiertas, sale la cola, y los brazos en su lugar, y el cuello y las orejas por su parte. Finalmente, es de la misma manera que un corsier con bardas (Arnés que se ponía antiguamente al caballo para su defensa en la guerra); e es del tamaño de un perrillo o gozque de estos comunes, y no hace mal, y es cobarde, y hacen su habitación en torronteras, y cavando con las manos ahondan sus cuevas y madrigueras de la forma que los conejos las suelen hacer. Son excelente manjar, y tómanlos con redes, y algunos matan ballesteros, y las más veces se toman cuando se queman los campos para sembrar o por renovar los herbajes para las vacas y ganados; yo los he comido algunas veces, y son mejores que cabritos en el sabor, y es manjar sano. No podría dejar de sospecharse si aqueste animal se hubiera visto donde los primeros caballos encubertados hubieron origen, sino que de la vista de estos animales se había aprendido la forma de las cubiertas para los caballos. (Fernández, 1959, p. 47).

\section{El mito: la palabra creadora}

Al principio de los tiempos, en la infancia de nuestra especie cuando los seres humanos empezábamos a ejercer el dominio de la naturaleza, cuando la observación era la base de la supervivencia los antepasados trataban de sobrevivir en un medio hostil, expuestos a las fieras y la inclemencia del tiempo.

Ante los fenómenos naturales avasalladores, era necesario explicar, con la palabra, el origen del mundo y de las cosas: ¿Quién nos puso aquí? ¿Cómo fue la creación del mundo y los seres humanos? Como resultado de la imaginación y acaso de los sueños, empezó con la explicación mágica de las fuerzas que avasallaban a las primeras comunidades en sus difíciles entornos.

Con el lenguaje incipiente nacieron los mitos de creación, con imágenes que trascendieron de generación en generación a través de las palabras convertidas en símbolos abstractos que permitían la comunicación de las ideas. La comunicación humana combina palabras, construye representaciones, les da diferentes significados según el contexto, comunica ideas, es mediada por la emoción, tiene la riqueza de la diversidad de lenguas, y es capaz de transformarse constantemente.

La palabra, la sonrisa y los sueños nos diferencian de los animales, aun de aquellos que 
aparentemente puedan tener posibilidades de expresión en algo semejantes a nuestra palabra. Ha habido gran controversia acerca de la emergencia de los lenguajes en el curso de la hominización, en alguna parte entre nuestra divergencia de los antropoides, hace unos cinco millones de años y la desaparición del Neandertal hace 50.000 .

Se sabe que muchos animales, como los insectos sociales, los pájaros, los lobos, los monos, etc., poseen sistemas de señales semióticas bastante desarrolladas, que les permiten comunicarse eficazmente.

La comunicación humana combina palabras, construye representaciones, les da diferentes significados según el contexto, comunica ideas, es mediada por la emoción y tiene la riqueza de la diversidad de lenguas, y es capaz de transformarse constantemente.

Todos los pueblos han generado explicaciones acerca de la creación del mundo. Entre nosotros es VI muy conocida la de la Biblia, que soporta gran parte de las convicciones religiosas de nuestra cultura, dice en Génesis 1; 2-5:

Y la tierra estaba desordenada y vacía, y las tinieblas estaban sobre la faz del abismo, y el Espíritu de Dios se movía sobre la faz de las aguas. Y dijo Dios: Sea la luz, y fue la luz. Y vio Dios que la luz era buena; y separó Dios la luz de las tinieblas. (Nácar y Colunga, 1961)

El Popol-Vuh, libro sagrado de los mayas, dice:

Todo estaba en suspenso, todo en calma, en silencio; todo inmóvil, callado, y vacía la extensión del cielo. No se manifestaba la faz de la tierra [...] Sólo el Creador, el Formador, Tepeu, Gucumatz, los Progenitores, estaban en el agua rodeados de claridad. Llegó aquí entonces la palabra, vinieron juntos [...] y hablaron entre sí [...] se pusieron de acuerdo, juntaron sus palabras y su pensamiento. [...] ¡Hágase así! ¿Que se llene el vacío ¡Que esta agua se retire y desocupe, que surja la tierra y que se afirme! [...] No habrá gloria y grandeza en nuestra creación y formación hasta que exista la criatura humana, el hombre formado. Así dijeron.
Entre los muiscas (Simón, 1821, p. 289) el pensamiento de Bague, la Gran Madre, se convirtió en obra, ya que antes no existía nada. Ella creó a los hacedores y formadores del mundo -Bachué, Cuza, Chibchacum, Bochica, Necamcatoa y sus seis hijos y la Trinidad de Chiminigagua-, y les dio la orden de crear el universo.

Para los esquimales,

En el principio había sólo oscuridad. Sin embargo, en esa penumbra ya existía el cuervo, acurrucado [...]. Con mucha precaución [...] empezó a arrastrarse, y por donde iba pasando, surgían las cosas: los arroyos, los ríos, los bosques [...]. Llenó todo de vegetación y de ríos, pero la oscuridad todavía lo cubría todo, hasta que descubrió un punto de luz [...] que se hacía más brillante a medida que lo desenterraba con el pico [...] lo arrojó al aire y el sol quedó suspendido, Ilenando todo de luz y permitiendo ver la hermosura de la creación. (Wood, 1987, p. 32)

Para los pieles rojas de la pradera antes la gente vivía en el cielo, y una doncella enfermó. Ningún médico acertaba a curarla, y el más anciano chamán de la tribu dijo que la curación estaba en las raíces del manzano sagrado. La doncella fue llevada allí y los médicos escarbaron alrededor del árbol, e hicieron un hueco tan profundo, que este cayó del cielo hasta el mundo, que entonces solo estaba cubierto de agua y no había tierra por ninguna parte. El árbol se hundió en el fondo del mar.

La doncella fue recogida por dos cisnes que nadaban, pero pronto se cansaron y pidieron que se reuniera el Consejo de los animales, presidido por la sabia tortuga.

Ella fue pidiendo a los mejores nadadores que buscaran la medicina sagrada para salvar la vida a la joven, pero ninguno encontró la medicina.

Solo Towskaye, la rana, Ilegó con la medicina en su boca: eran unos granitos de tierra, que escupió y murió por el esfuerzo. La tortuga declaró a Towskaye animal sagrado, y luego pidió a los demás animales que esparcieran esos granos de tierra sobre su caparazón. Así se formó la Tierra, y la doncella se curó e invitó a la demás gente del cielo a vivir en el bello mundo creado por los animales. 
El mito del pueblo Fon de África alude a Aida-Hwedo la serpiente cósmica, que sostiene el mundo, enroscada como si fuera un cojín para poder transportarlo.

\section{Aplicación literaria del mito de creación}

Un cuento de Celso Román (2010) puede ilustrarnos acerca de la capacidad de la palabra para generar realidades en nuestra mente. Se titula "Ocurrió en la arena" y narra la historia de una botella que un día llegó a una playa. Había salido hacía muchísimo tiempo de una isla desde donde un náufrago la enviara con un mensaje de amor. Con el paso del tiempo el papel con el mensaje se deshizo, pero el amor pasó a ser parte de ella, dándole vida. En una noche de luna llena llegó a una playa, donde la encontró un cangrejo, que con sus pinzas la alejó del oleaje. Allí conversaron y la botella le contó su historia. El cangrejo la escuchó atentamente y a su turno también le habló de su vida, de sus sueños y de su soledad, comentando apesadumbrado que a él nadie lo quería. La botella propuso que fueran amigos y así el mensaje de amor que ella traía estaría llegando a un destino haciendo feliz a alguien, y él tendría con quién compartir alegrías y tristezas. Así lo hicieron, pasaron de la amistad al noviazgo y del noviazgo al matrimonio. Poco tiempo después, y como le pasa a los que se quieren tanto, empezaron a tener hijos. Eran bastante extraños; no eran feos, porque a todos los padres sus hijos siempre les parecen bellos, pero a los vecinos sí les parecieron como raros porque eran así: (se muestran gafas) No tenían tantas patas como el papá cangrejo, ni eran todos de vidrio como la mamá botella.

Entonces sucedió que a aquella lejana playa llegó tropezando alguien que no podía ver bien y encontró por casualidad uno de los hijos del cangrejo y la botella, y como debía hacer siempre por lo corto de su visión, lo acercó a sus ojos y miró a través de las transparentes conchas de cristal del animalito y fue como un milagro:

Pudo ver perfecto la belleza de este mundo. Las personas con visión defectuosa los Ilamaron ante-ojos y los juzgaron hermosos, y los llevaron gustosos en el rostro, a pesar de ese aspecto de cangrejo de dos patas, agarrándose de las orejas, abrazando la cabeza de los agradecidos hombres de corta vista.
Crear un mundo implica generarle sus propias reglas de comportamiento. Su geografía, su historia, sus leyes sociales, su lógica interna, para hacerlo creíble.

\section{La leyenda, encuentro de dioses y} humanos

Colombia es rica en leyendas por ser el resultado de una mezcla de genes provenientes de América, Europa y África, y en el último siglo con Asia gracias a la globalización económica y la expansión comercial de la China y los países del Lejano Oriente. La leyenda campesina convoca y crea seres mágicos como la Patasola, la Muelona, la Madre de Agua, el Mohán, el Hojarasquín del Bosque, la Bola de Fuego, María la Larga, el Patetarro, el silbón y el Tunjo, además de los duendes y las brujas, que son descendientes directos de los conquistadores españoles encontrándose en el trópico americano con los dioses indígenas y africanos. Las leyendas imponen comportamientos sociales y pedagógicamente se pueden volver positivos.

El tunjo es un ejemplo: se aparece como un bebé que llora a la orilla de los caminos de herradura, y cuando el viajero lo levanta, él lo mira con ojos rojos como carbones encendidos, le muestra enormes colmillos y le dice: “Usted es mi papá y yo tengo ñentes", lanzando una bocanada de fuego. Si el jinete no se detiene, el tunjo lo persigue hasta que lo alcanza. La manera de neutralizarlo es hacerle en la frente la señal de la Santa Cruz y bautizarlo, para que se convierta en la figura de oro muisca.

\section{Los cuentos de hadas y populares}

Los cuentos populares, folclóricos, hadas, tradicionales o relatos maravillosos narran historias sucedidas a los seres humanos, simple y llanamente y son el resultado de la confluencia de innumerables creaciones de la humanidad a lo largo de los siglos y las diferentes culturas, que por diversos caminos han llegado hasta nosotros. Tienen una estructura común, analizada por Vladimir Propp (véase 1998a; 1998b), en la cual se presentan hasta 31 funciones de los personajes, que se pueden resumir en los siguientes elementos: el héroe es escogido para cumplir 
una misión; aparecen donantes o benefactores y enemigos o transgresores, que le ayudan o tratan de destruirlo usando objetos mágicos; y el protagonista debe sobrepasar diversas pruebas en su camino hasta llegar al desenlace, la misión cumplida, la consecución de la felicidad, el amor y la riqueza.

Rocío Vélez de Piedrahita (1986) enumera cómo los cuentos populares europeos se nutrieron de personajes como los dragones y la Cenicienta, venidos desde la China con los mercaderes por la Ruta de la Seda; de la India por el camino de las especias y durante las cruzadas Ilegaron perfumes mágicos, alfombras voladoras, genios, manjares abundantes, ogros, talismanes y culebras de siete colas; de Persia y Arabia Ilegaron las Mil y una noches con relatos populares cantados por los juglares durante los siglos X, XI y XII a una Europa donde ya estaban las fábulas del griego Esopo y los numerosos seres de la mitología celta como hombrecitos, enanos, elfos, troles, príncipes, princesas, los caballeros de la Mesa Redonda del rey Arturo, el mago Merlín, y el hadas Morgana, además de espadas, escudos y sortilegios mágicos. En los siglos XVIII y XIX Europa inició la recopilación de los cuentos populares en las obras y adaptaciones de G. B. Basile, Charles Perrault, los hermanos Jacob y Wilhelm Grimm, Hans Christian Andersen, y los cuentos populares noruegos de P. S. Absjörsen, J. Jacobs y J. E. Moe. España tuvo la influencia de ocho siglos de ocupación mora en los califatos de Granada y Al Andalus, Andalucía, que llegó a América con los misioneros y los conquistadores, portadores de romances, ánimas, apariciones y espantos que se fundieron con los mitos indígenas y el bagaje cultural de los africanos traídos a la fuerza como esclavos, quienes aportaron la santería, los sortilegios y brujerías, monstruos de la selva y personajes como el tío conejo y el tío tigre.

Entre los muchos recopiladores de cuentos tradicionales están don Tomás Carrasquilla ("Por aguas y pedrejones"), Antonio Molina Uribe ("A echar cuentos pues"), Euclides Jaramillo Arango ("Las aventuras del pícaro tío Conejo"), Agustín JaramiIlo Londoño ("Cosecha de cuentos") y José Antonio León Rey ("El pueblo relata").
El psicoanalista Bruno Bettelheim (1994) da una enorme importancia a los cuentos de hadas por cuanto ellos hablan al inconsciente profundo del niño preparándolo para enfrentar positivamente las problemáticas que se le han de presentar en la vida adulta, además de considerarlos obras de arte, que enseñan acerca de las dificultades y nos preparan para encontrarnos a nosotros mismos:

[...] la eventual salvación, la completa restauración y la elevación del niño-héroe a una condición superior de existencia, son características de los cuentos de hadas. En tanto que obras de arte, su propósito es no solo enseñarnos que la vida es difícil e implica frecuentemente peligrosas batallas, sino también que solo dominando las sucesivas crisis de nuestra existencia seremos capaces de encontrarnos a nosotros mismos.

\section{La oralidad como recurso pedagógico y lúdico}

El conferencista propone un ejercicio de redacción del cuento "Runchitos al colegio", a partir de imágenes en las cuales se referencien valores relacionados con el conocimiento y el cuidado de la naturaleza y la pedagogía para desarrollar la capacidad de comunicar verbalmente los pensamientos, en un acercamiento a la narración oral, un arte tradicional tan antiguo que se pierde en la memoria del tiempo, cuando las tribus se reunían junto al fuego para hablar del día de trabajo, de sus antepasados o de sus dioses.

La charla se cierra con un análisis de Palabras tóxicas, palabras benevolentes, las ocho reglas de la ética del lenguaje de Michel Lacroix (2010), filósofo de la ética de las relaciones:

1. Mi palabra debe ser cordial: debo saludar, despedirme, dar las gracias.

2. Mi palabra debe ser amable: debo dejar en el aire una suerte de puntos suspensivos para que el otro se exprese; no debo ridiculizar a nadie en público.

3. Mi palabra debe ser positiva: debo ser una fuente de inspiración para los demás.

4. Mi palabra debe ser respetuosa de los ausentes: debo evitar el encadenamiento incesante 
de juicios sobre los demás, como si la conversación fuera un tribunal virtual.

5. Mi palabra debe ser tolerante: debo exponer mi punto de vista de manera no violenta, escuchar las opiniones distintas a la mía; la buena voluntad de discutir y escuchar es el fundamento de la democracia.

6. Mi palabra debe ser la guardiana del mundo: debo mostrar admiración por lo que me rodea, el mundo natural y el social. Es mejor el exceso de admiración que el exceso de desprecio.

7. Mi palabra debe ser responsable del lenguaje: debo hablar bien mi lengua materna, emplear la palabra exacta, respetar la gramática y la pronunciación, tratar de expresarme con elegancia y refinamiento.

8. Mi palabra debe ser verdadera: debo evitar la mentira, los eufemismos hipócritas y las exageraciones injustas.

\section{Referencias}

Anónimo. (2007). Popol Vuh - Poopol Wuuj: $K^{\prime}$ ichee'. Edición bilingüe. Albertina Saravia (ed.); Rodrigo Guarchaj (trad.). Ciudad de Guatemala: Piedra Santa.
Bettelheim, B. (1994). Psicoanálisis de los cuentos de hadas. Silvia Furió (trad.). Barcelona: Crítica, Grijalbo, Mondadori.

Fernández, G. (1959). Historia general y natural de las Indias. Edición y estudio preliminar de Juan Pérez de Tudela Bueso. Madrid: Atlas.

Lacroix, M. (2010). Paroles toxiques, paroles bienfaisantes. Pour une éthique du langage. París: Robert Laffont.

Maturana, H. (1997). El sentido de lo humano. $9^{a}$ ed. Santiago de Chile: Comunicaciones Noreste.

Nácar, E.; Colunga, A. (trad.). (1961). Sagrada Biblia. Madrid: Biblioteca de Autores Cristianos, B.A.C.

Propp, V. (1998a). Las raíces históricas del cuento. $4^{\mathrm{a}}$ ed. Madrid: Fundamentos.

Propp, V. (1998b). Morfología del cuento. Madrid: Akal.

Román, C. (2010). Fu, el protector de los artistas y otros relatos. Bogotá: Panamericana.

Simón, P. (1821). Noticias historiales. Bogotá: Casa Editorial de Medardo Rivas.

Vélez, R. (1986). Guía de literatura infantil. Mede- IX Ilín: Secretaría de Educación y Cultura.

Wood, M. (1987). Espíritus, héroes y cazadores de la mitología de los indios norteamericanos. John Sibbick (il.); Juan Manuel Ibeas (trad.). Madrid: Anaya. 